\title{
O uso da ginástica laboral na promoção à saúde do agente comunitário de saúde
}

\author{
Beatriz Bezerra dos Santos Cardoso
}

\section{RESUMO}

O Agente Comunitário de Saúde (ACS) é o principal elo entre a comunidade e a Unidade de Saúde, no território onde está inserido. Sua dinâmica laboral pode gerar sobrecarga emocional e física que podem impactar negativamente na sua saúde, tornando-se necessária a realização de ações direcionadas à saúde desse trabalhador. Diante disso, o objetivo do presente trabalho é relatar a experiência de sessões de Ginástica Laboral (GL) com ACS de uma Unidade de Saúde da Família no município de Itabuna-BA. As sessões de Ginástica Laboral promoveram bem-estar, valorização da saúde do trabalhador e interação grupal. Ações continuadas de promoção à saúde são imprescindíveis para esses profissionais, que muitas vezes têm sua saúde negligenciada pelo serviço de saúde.

Palavras-chave: ginástica laboral; promoção à saúde; agente comunitário de saúde; saúde do trabalhador; unidade de saúde da família.

Revista da Rede APS 2021

Publicada em: 20/09/2021

DOI:10.14295/aps.v3i2.140

Beatriz Bezerra dos Santos (Universidade Estadual de Santa Cruz, Ilhéus, BA Brasil)

Correspondência para:

Beatriz Bezerra dos Santos beatrizbezerracardozo@gmail.com

\section{ABSTRACT}

The Community Health Agent (CHA) is the main link between the community and the Health Unit, in the territory where it is inserted. Their work dynamics can generate emotional and physical overload, which can negatively impact their health, making it necessary to carry out actions directed to the health of this worker. Therefore, the objective of the present work is to report the experience of Labor Gymnastics (GL) sessions with CHW from a Family Health Strategy, in the municipality of Itabuna- BA. The Labor Gymnastics sessions promoted well-being, valuing the health of the worker and group interaction. Continued actions to promote health are essential for these professionals, who often have their health neglected by the health service.

Keywords: labor gymnastics; health promotion; community health agent; worker's health; family health strategy. 


\section{INTRODUÇÃO}

A Ginástica Laboral (GL) é uma modalidade de atividade física praticada dentro do local de trabalho, também conhecida como ginástica compensatória, ginástica do trabalho ou de pausa. Seu objetivo maior é criar um espaço para a melhoria do condicionamento físico dos trabalhadores, quebrando o ritmo das tarefas repetitivas e da monotonia e primordialmente, prevenir o surgimento de doenças ocupacionais. $\mathrm{Na}$ intenção de promover a saúde do trabalhador por meio da prática de exercícios físicos, a GL pode proporcionar o autoconhecimento, melhora da autoestima, e possíveis melhorias do convívio social no ambiente ocupacional (SERRA, PIMENTA, QUEMELO, 2014; LAUX et al., 2016).

$\mathrm{Na}$ literatura, são escassos os estudos a respeito da Ginástica Laboral com profissionais ligados à saúde, especificamente em relação aos profissionais da Atenção Básica ( $A B)$, sendo mais comuns pesquisas voltadas à prática de $G L$ em indústrias e empresas. Esse fato pode ter relação com a origem da prática, surgida em 1925 na Polônia, onde era conhecida como ginástica de pausa e ofertada a operários, no entanto, o seu desenvolvimento ocorreu no Japão no ano de 1928, onde os servidores dos correios compareceram às sessões de ginástica diariamente (KRETZSCHMAR, BEZERRA, BRITO, 2012).

No que concerne a Atenção Básica $(A B)$ de acordo a Política Nacional de Atenção Básica (PNAB), aprovada por meio da Portaria no 2.436 de 21 de setembro de 2017, essa é caracterizada como um conjunto de ações de saúde, no campo individual e coletivo, que abrangem a promoção e a proteção da saúde, a prevenção de agravos, o diagnóstico, o tratamento, a reabilitação e a manutenção da saúde (BRASIL, 2017). No cenário da $A B$, surgiu o Agente Comunitário de Saúde (ACS) através do Programa de Agentes Comunitários de Saúde (PACS), efetivamente instituído e regulamentado pelo Ministério da Saúde em 1997, entretanto, a profissão só foi regulamentada no ano de 2002, pela Lei 10.501 (BRASIL, 2001; LEVY, MATOS, TOMITA, 2004). Esse profissional tem uma rotina de trabalho singular e desgastante, o que demanda estratégias para promoção do seu bem-estar. A Ginástica Laboral por ser uma ferramenta de baixo custo, pouca duração, fácil realização e com muitos benefícios, pode ter um impacto positivo na saúde do ACS.

O Agente Comunitário de Saúde configura-se um elo entre a comunidade e a unidade de saúde, através de uma prática peculiar e complexa, proporcionando a articulação do serviço de saúde com a população. É o componente da equipe que possui maior contato com a população, adentra os lares, recebe diretamente as queixas das pessoas, comprometendo-se diretamente com a necessidade de dar respostas e encaminhamentos aos problemas encontrados, ao mesmo tempo em que necessita confrontarse com a equipe e agir de acordo com suas possibilidades e limites do próprio sistema de saúde (PERES et al., 2010).

Essa profissão traz várias peculiaridades em seu cotidiano com destaque para a sobrecarga emocional que os ACS estão expostos, ligada tanto à pressão feita pela comunidade do território e pela equipe de saúde acerca de seu trabalho, quanto pela sensação de impotência, em determinados momentos, diante da pouca resolutividade das demandas visualizadas no ambiente onde trabalham. Além disso, vale ressaltar a demanda física presente no processo de trabalho, decorrente de extensos trajetos percorridos com ladeiras íngremes e ruas irregulares em visitas domiciliares, ataques de animais e condições climáticas adversas, e o contato com áreas e eventos perigosos (pontos de droga e episódios de violência) (SANTOS, HOPE, KRUG, 2019; ALMEIDA, BAPTISTA, SILVA, 2016).

A dinâmica laboral vivida pelos Agentes Comunitários de Saúde pode gerar pressões e sobrecarga, tornando-os susceptíveis a riscos psíquicos e ergonômicos associados diretamente com vários distúrbios, dentre os quais as doenças osteomusculares relacionadas ao trabalho (DORT), que contribuem negativamente para sua saúde física e mental, e também interferem na eficácia do trabalho 
realizado. Desse modo, faz-se necessária a adoção de ações direcionadas à saúde desse trabalhador. Partindo desse pressuposto, o uso da ginástica laboral por meio de práticas promotoras de saúde pode contribuir positivamente para o bem-estar destes profissionais através da redução do estresse, atenuação do sedentarismo, redução da ocorrência dos distúrbios ocupacionais e maior integração social. Assim, o objetivo deste trabalho é relatar a experiência de sessões de ginástica laboral, com Agentes Comunitários de Saúde de uma Unidade de Saúde da Família, no município de Itabuna-BA.

\section{MATERIAIS E MÉTODOS}

Trata-se de um relato de experiência, de caráter descritivo e reflexivo, elaborado a partir da vivência de sessões de Ginástica Laboral com Agentes Comunitários de Saúde, em uma Unidade de Saúde da Família (USF) composta por duas equipes incluindo quatorze ACS. A USF encontra-se localizada no município de ItabunaBa, região sul da Bahia.

As ações desenvolvidas foram organizadas através da percepção das necessidades dos trabalhadores envolvidos. As sessões de Ginástica Laboral foram realizadas durante três meses (no período de agosto a novembro de 2019), três vezes por semana, no período matutino (período que antecedia a saída dos ACS para o território) e duração média de vinte minutos. Os ACS encontram-se na USF nos primeiros horários da manhã, posteriormente seguem para o território e na maioria das vezes não retornam mais para USF pela manhã. Dessa forma, foi utilizada Ginástica Laboral do tipo Preparatória ou de Aquecimento, a qual é feita no início do trabalho e prepara o trabalhador para a jornada de trabalho, promovendo disposição e sensação de bem-estar (KRETZSCHMAR, BEZERRA, BRITO, 2012).

As práticas da GL foram realizadas dentro da sala dos ACS. No primeiro momento, foram explicados o conceito e os benefícios proporcionados pela prática. A Ginástica Laboral foi composta por: exercícios ativos livres de membros superiores e inferiores, alongamento global muscular, de membros superiores e membros inferiores, com foco em cadeias musculares mais exigidas durante a jornada de trabalho, movimentos da cintura escapular combinados (elevação, depressão, protração e retração) movimentos pélvicos (anteversão e retroversão pélvica), exercícios de coordenação e equilíbrio, exercícios respiratórios, bem como ensino à respiração diafragmática.

As atividades foram feitas em grupo, com o objetivo de promover a interação e motivação entre os ACS. Em alguns momentos, realizou-se exercícios em dupla. Além disso, com a intenção de tornar as sessões mais prazerosas e dinâmicas, utilizou-se de recursos como bolas de borracha e músicas. Os exercícios eram explanados verbalmente e demonstrados para que os profissionais pudessem ter melhor compreensão dos movimentos para posteriormente executá-los. Foi dado estímulo quanto à postura adequada e correção de compensações musculares, além de incentivo à respiração diafragmática.

\section{DESCRIÇÃO DA EXPERIÊNCIA}

A primeira sessão de $\mathrm{GL}$ constou com a maioria dos Agentes Comunitários de Saúde, entretanto ao decorrer dos encontros a quantidade diminuiu, mantendo-se normalmente em torno de seis participantes, de um total de quatorze ACS. Em um trabalho realizado por Grande e Silva (2014), com trabalhadores participantes e não participantes de um programa de $G L$, verificou-se que as principais barreiras autorreferidas para a prática da Ginástica Laboral foram, o fato de os trabalhadores não gostarem da intervenção e ausência de tempo.

No presente estudo, acredita-se que a falta de ações voltadas para a saúde do Agente Comunitário pode ter influenciado negativamente para maior adesão da proposta, uma vez que este não tem o hábito de praticar exercício físico no trabalho. Além disso, pode-se observar comportamento de evitação de alguns profissionais em relação à prática, demonstrado no ato de saírem do local no momento da 
atividade, bem como não adentrarem no espaço durante a prática.

Nas primeiras práticas, os ACS apresentavam dificuldade de concentração, demonstrada por conversas paralelas em relação a vários assuntos e dispersão; dessa maneira eram constantemente orientados a manterem o foco e se concentrarem na atividade realizada. Ao longo das sessões esse aspecto foi melhorado. Tal dificuldade pode ter influência de sobrecarga mental e física, uma vez que muitos destes profissionais estão com férias acumuladas e muitas demandas a resolverem, e da falta de hábito de reservarem um tempo para si próprio. Além disso, em vários momentos alguns participantes eram interrompidos por outros funcionários da Unidade, principalmente para atenderem usuários da sua microárea, no entanto a atividade seguia normalmente com os outros participantes.

No transcorrer das sessões realizadas, observouse ânimo e incentivo grupal para a realização da prática da GL e houve alguns relatos informais positivos a respeito da atividade. O "ACS 1" relatou: "quando eu faço a ginástica não preciso tomar remédio pra ansiedade"; em outro momento, o "ACS 2" expôs: "estou melhor da dor nos ombros".

Percebeu-se também grande valorização profissional vinda dos ACS, expressados por meio de agradecimentos e motivação para as sessões posteriores. Também notou-se a interação e empolgação entre os colegas, bem como episódios de descontração e colaboração, demonstrada no ato de cooperarem uns com os outros com a execução correta dos exercícios.

Gondim et al (2009) realizaram um estudo que objetivou conhecer aspectos relacionados à saúde ocupacional de funcionários de um hospital público e avaliar a prática de ginástica laboral bem como sua influência na qualidade de vida no trabalho. Os autores concluíram que a GL atendeu às necessidades da maioria dos participantes, que observaram mudanças significativas em seu cotidiano laboral, como melhoria na performance no trabalho, decorrente do aumento da disposição para trabalhar e melhoria na postura.
Silva et al. (2017) realizaram ações de prevenção e promoção à saúde que incluíram discussão de temas como ginástica laboral e ergonomia para profissionais de três Unidades Básicas de Saúde, e perceberam melhora no desempenho, na eficácia do trabalho e redução da tensão do cotidiano dos trabalhadores; houve ainda, a orientação aos profissionais quanto à relevância da ginástica laboral e estímulo a sua realização pelo menos três vezes por semana e o uso da zumba. Tais achados corroboram com o presente estudo, o qual orientou que os trabalhadores continuassem nos domicílios a realização dos exercícios feitos na USF.

Ao longo da experiência, houve a preocupação em tornar as práticas de GL cada vez mais estimulantes, de modo que a cada sessão eram propostos novos exercícios e músicas, que promoveram entusiasmo durante a prática das atividades. Segundo Alves e Nascimento (2016), a relação entre a música e as atividades motoras tem sido reconhecida tanto em sujeitos em reabilitação, como para praticantes de atividade física, cuja intenção é a manutenção da saúde.

Portanto, observa-se que a Ginástica Laboral é uma estratégia relevante para promoção da saúde do ACS.

\section{CONSIDERAÇÕES FINAIS}

As estratégias de promoção à saúde na Atenção Básica geralmente são voltadas para o usuário, entretanto o Agente Comunitário de Saúde como elo entre a comunidade e o serviço merece atenção em relação à sua saúde, uma vez que um funcionário saudável e motivado reflete no seu cotidiano de trabalho, consequentemente na qualidade do serviço prestado à população.

A baixa adesão às atividades propostas observadas neste estudo, requer um trabalho posterior de educação em saúde do trabalhador principalmente direcionado ao ACS, com atenção da gestão municipal. Ações integradas com profissionais de outros campos também podem agregar valor, promover a regularidade da atividade e estimular a participação e maior 
adesão de ACS. Dessa forma, torna-se útil refletir estratégias futuras que visem otimizar a adesão de ações relacionadas à saúde profissional, incluindo também outros profissionais para uma efetiva atenção integral ao trabalhador.

A prática da ginástica laboral resultou na melhoria do bem-estar dos ACS e maior interação entre o grupo, demostrando que são imprescindíveis ações continuadas de promoção em saúde para esses profissionais que na maioria das vezes, têm sua saúde negligenciada pelo serviço onde estão inseridos. Através de iniciativas simples e de baixo custo como demonstradas neste relato, os trabalhadores podem sentirem-se motivados e valorizados. Assim, torna-se relevante tomar esta experiência como exemplo positivo para intervenções posteriores, exprimindo a importância da valorização deste profissional. 


\section{REFERÊNCIAS}

ALMEIDA, Mirian Cristina dos Santos; BAPTISTA, Patrícia Campos Pavan, SILVA, Arlete. Cargas de trabalho e processo de desgaste em Agentes Comunitários de Saúde. Rev. Esc. Enferm. USP, v. 50, n.1, p. 95-103, fev. 2016.

Disponível em: http://www.scielo.br/scielo.php?script=sci_arttext\&pid=S008062342016000100093\&lng=en\&nrm=iso. Acesso em: 05 fev. 2020.

ALVES, Jailson do Nascimento; NASCIMENTO Deise Cristiane do. Dança de Zumba como instrumento em prol da saúde e do bem estar para comunidades periféricas do Município. Revista Multidisciplinar e de Psicologia, v. 10, n. 30, jul. $2016 . \quad$ Disponível em: https://idonline.emnuvens.com.br/id/article/view/449/622. Acesso em: 02 fev. 2020.

BRASIL. Ministério da Saúde. Portaria no 2.436, de 21 de setembro de 2017. Brasília: Diário Oficial da República Federativa do Brasil, $2017 . \quad$ Disponível em: https://www.nescon.medicina.ufmg.br/biblioteca/imagem/portaria2436.pdf. Acesso em: 04 ago. 2021.

BRASIL, Ministério da Saúde. Programa agentes comunitários de saúde (PACS). Brasília: Ministério da Saúde, 2001. Disponível em: http://bvsms.saude.gov.br/bvs/publicacoes/pacs01. Acesso em: 30 jan. 2020.

GONDIM, Kamilla de Mendonça et al. AVALIAÇÃO DA PRÁTICA DE GINÁSTICA LABORAL PELOS FUNCIONÁRIOS DE UM HOSPITAL PÚBLICO. Revista Rene, v. 10, n. 2, p. 95-102, abr./jun. 2009. Disponível em: http://periodicos.ufc.br/rene/article/view/4778/3537. Acesso em: 01 fev. 2020.

GRANDE, Antônio José; SILVA, Valter. Barreiras e facilitadores para a adesão à prática de atividade física no ambiente de trabalho. Revista 0 Mundo da Saúde, v. 38, n. 2, p. 204-209, 2014. Disponível em: http://bvsms.saude.gov.br/bvs/artigos/mundo_saude/barreiras_facilitadores_adesao_pratica_atividade s.pdf. Acesso em: 17 ago. 2019.

KRETZSCHMAR, Magda Alecssandra; BEZERRA, Gabriela das Chagas; BRITO, Larissa Ribeiro. GINÁSTICA LABORAL, UMA OPÇÃO PARA O FISIOTERAPEUTA E NOVA PERSPECTIVA PARA INSTITUIÇÕES DE ENSINO. Revista UNILUS Ensino e Pesquisa, v. 9, n. 17, jul./dez, 2012. Disponível em: http://revista.unilus.edu.br/index.php/ruep/article/view/63/u2012v9n17e63. Acesso em: 17 ago. 2019.

LAUX, Cunha Rafael et al. Programa de Ginástica Laboral e a Redução de Atestados Médicos. Revista Cienc Trab., Santiago, v. 18, n. 56, p. 130-133, ago. 2016. Disponível em: https://scielo.conicyt.cl/scielo.php?script=sci_arttext\&pid=S071824492016000200009\&lng=es\&nrm=iso . Acesso em: 17 ago. 2019.

LEVY, Flávia Mauad; MATOS, Patrícia Elizabeth de Souza; TOMITA, Nilce Emy. Programa de agentes comunitários de saúde: a percepção de usuários e trabalhadores da saúde. Cad. Saúde Pública, v. 20, n. 01, p. 197-203, fev. 2004. Disponível em: http://www.scielo.br/scielo.php?script=sci_arttext\&pid=S0102311X2004000100036\&Ing=en\&nrm=iso. Acesso em: 10 dez. 2019.

PERES, Cassia Regina Fernandes Biffe et al. SER AGENTE COMUNITÁRIO DE SAÚDE: MOTIVAÇAO E SIGNIFICADO. Revista Mineira de Enfermagem, v. 14, n. 4, p. 559-565, out./dez, 2010. Disponível em: http://www.reme.org.br/artigo/detalhes/151. Acesso em: 13 out. 2019.

SANTOS, Amanda Corrêa dos; HOPPE, Ariane dos Santos e KRUG; Suzane Beatriz Frantz. Agente Comunitário de Saúde: implicações dos custos humanos laborais na saúde do trabalhador. Physis, v. 28, n. $04, \quad$ p. $1-12, \quad 2018 . \quad$ Disponível em: http://www.scielo.br/scielo.php?script=sci_arttext\&pid=S010373312018000400602\&lng=en\&nrm=iso. Acesso em: 10 dez. 2019.

SERRA, Maysa Venturoso Gongora Buckeridge; PIMENTA, Lorrana Campos; QUEMELO, Paulo Roberto Veiga. EFEITOS DA GINÁSTICA LABORAL NA SAÚDE DO TRABALHADOR. Revista Pesquisa em Fisioterapia, 
v. 4, n. $3, \quad$ p. $197-205, \quad 2014$ Disponível em: https://www5.bahiana.edu.br/index.php/fisioterapia/article/view/436/361. Acesso em: 17 ago. 2019.

SILVA, Débora Alves et al. PROMOÇÃO E EDUCAÇÃO EM SAÚDE PARA TRABALHADORES DE UNIDADES BÁSICAS DE SAÚDE: RELATO DE EXPERIÊNCIA. Revista de Enfermagem e Atenção à Saúde, v. 6, n. 2, p.

153-160, jul./dez. $2017 . \quad$ Disponível em:
http://seer.uftm.edu.br/revistaeletronica/index.php/enfer/article/view/1837/pdf. Acesso em: 02 fev. 2020. 